\title{
Resultados y modelación numérica de ensayos de carga usando una celda de Osterberg en Concón, Chile
}

\author{
Results and numerical modelling of Osterberg cell load testing in Concón, Chile
}

Fecha de entrega: 23 de abril 2014

Fecha de aceptación: 14 de agosto 2014

\section{Dennis Raddatz ${ }^{1,2}$, Cesar Araya ${ }^{3}$ y Oscar Taiba ${ }^{1}$}

\author{
${ }^{1}$ Ferrara - Proyectos Especiales, Rengo 1270, Nuñoa, Chile, oscartaiba@ferrara.cl \\ ${ }^{2}$ Department of Civil and Environmental Engineering, University of Massachusetts, 130 Natural Resources Road, Amherst, MA \\ 01003, USA, draddatzalta@engin.umass.edu \\ ${ }^{3}$ Sica Ingenieros Asociados, Chorrillos 1137, Linares, Chile, caraya@sica-ingenieria.cl
}

Se explica como funciona una celda de carga de Osterberg O-cell, usada para ensayos de gran carga en dirección axial en pilotes. Su principal ventaja es queno se requiere la aplicación de una carga en la superficie y se obtienen las capacidades por fuste y punta de forma directa y por separado. Se entregan los antecedentes y resultados de un ensayo de carga realizado con O-cell en la Refinería de Concón, en pilotes de fundación de gran tamaño. Los datos registrados en terreno fueron utilizados para calibrar un modelo numérico del ensayo, realizado en el programa computacional de elementos finitos Plaxis 2D. Finalmente se realiza un modelo numérico de un ensayo de carga tradicional, cuyo resultado es comparado con la curva equivalente obtenida con los datos del ensayo de carga O-cell.

Palabras clave: celda de Osterberg O-cell, pilotes, ensayos de carga bidireccional
The operation of an Osterberg cell O-cell used for testing piles with large load in the axial direction is explained. Its main advantage is that it does not require the application of a load on top of the pile. The capacities are obtained for shaft and tip directly and separately. This paper shows the background and results of a series of tests performed with $O$-cell in foundation piles of great size in the Concon refinery. The data recorded in the field were used to calibrate a numerical model of the test using the finite element software Plaxis 2D. Finally, it is performed a numerical model of a traditional load test, which is compared to the equivalent curve for a traditional test carried out with the data of the executed O-cell load test.

Keywords: Osterberg cell O-cell, piles, bidirectional load tests

\section{Introducción}

Cuando el suelo cerca de la superficie tiene baja capacidad de soporte o es muy compresible para asegurar un asentamiento admisible mínimo de la estructura proyectada, se deben considerar soluciones geotécnicas como fundaciones profundas, que en la mayoría de los casos se refiere a pilotes de fundación (Peck et al., 1974). Entre las pruebas que se pueden hacer en los pilotes, se encuentran las pruebas de integridad y pruebas de carga (Candogan, 2009). Las pruebas de integridad se realizan en una fracción del total de los pilotes para evaluar la calidad de la construcción de los pilotes. Las pruebas de carga pueden ser estáticas o dinámica, con ellas se obtienen las relaciones de carga y deformación, además de los valores de carga última o si los pilotes actúan por punta y/o fuste. En proyectos de gran envergadura se deben realizar las pruebas de carga necesarias para calibrar los modelos de comportamiento de la estructura geotécnica (Das, 2012). Para el caso de pilotes de fundación, es necesario evaluar en terreno la capacidad de carga axial (vertical) y lateral.

Uno de los métodos para evaluar la capacidad axial de pilotes es el método O-Cell (celda de carga de Osterberg), el que consiste en una celda de carga que tiene una alta capacidad que se instala con la armadura del pilote previo al hormigonado (Ellman y Rhyner, 2009). Una vez que el pilote ya se encuentra hormigonado, la celda O-cell utiliza un impulso hidráulico para desplazar el pilote tanto en dirección ascendente como descendente de manera de 
identificar la capacidad de carga axial del pilote, tanto por fuste como por punta. El Dr. Jorj Osterberg desarrolló y patentó esta prueba que lleva su nombre, sistema que fue usado por primera vez el año 1984 en un pilote de prueba (Schmertmann y Hayes, 1997). La primera aplicación en un proyecto fue realizada por la empresa Haley \& Aldrich en un pilote de acero en un puente sobre el río Saugus, en Massachussets, al noreste de EEUU. Su primera aplicación en pilotes de hormigón fue realizada por la empresa Schmertmann \& Crapps el año 1988, en pilotes de un puente en Florida, EEUU. El uso de la celda O-cell se empezó a masificar a partir del año 1996, cuando empresas especializadas empezaron a distribuirla y a entregar el servicio de instalación del sistema y ejecución de los ensayos. La celda de carga de Osterberg ha evolucionado en el tiempo, destacando el aumento de capacidad de las celdas, hoy día se pueden alcanzar niveles de carga que harían técnica y económicamente impracticable un ensayo usando un sistema diferente al O-cell (Aydin et al., 2011).

\section{Prueba de carga con 0-cell}

Dos de las principales ventajas de la prueba de carga O-cell es la económica y la reducción del área de trabajo, ya no es necesario usar grandes y costosas estructuras para aplicar una carga en la superficie como sucede en el caso de ensayos tradicionales para cargas altas (Schmertmann y Hayes, 1997). Usualmente, en los ensayos de carga de Osterberg se ubica una celda de carga en la punta del pilote, aplicándose una carga ascendente y otra descendente de forma simultánea (Zuo et al., 2004). En casos particulares se puede usar más de una celda por pilote ensayado, específicamente cuando se desee evaluar con precisión la variación de la capacidad por fricción en diferentes tramos de un pilote (Castelli y Wilkins, 2004).

La Figura 1a muestra el ensayo de carga tradicional y la Figura $1 \mathrm{~b}$ el ensayo de carga de Osterberg con el cual se obtienen las contribuciones de resistencia por fricción en el fuste y por punta del pilote por separado (Zuo et al., 2004). Las aplicaciones de las cargas se producen hasta que se alcanza la falla por fricción o en la punta del pilote (Coduto, 2000). Si la falla se produce por punta, se debe extrapolar la información obtenida hasta ese momento para obtener la capacidad última por fricción. Por otro lado, si la falla que se produce primero es por fricción (carga ascendente), se puede aplicar una carga externa en la parte superior del pilote de manera de contrarrestar la carga ascendente (falla por fuste) y así continuar la prueba hasta que se produzca la falla en la punta del pilote. El ensayo de carga de Osterberg se puede utilizar también para cuantificar la capacidad de carga al usar mejoras de terreno, como lo son el uso de lechada inyectada en la base de pilotes (Castelli y Wilkins, 2004).
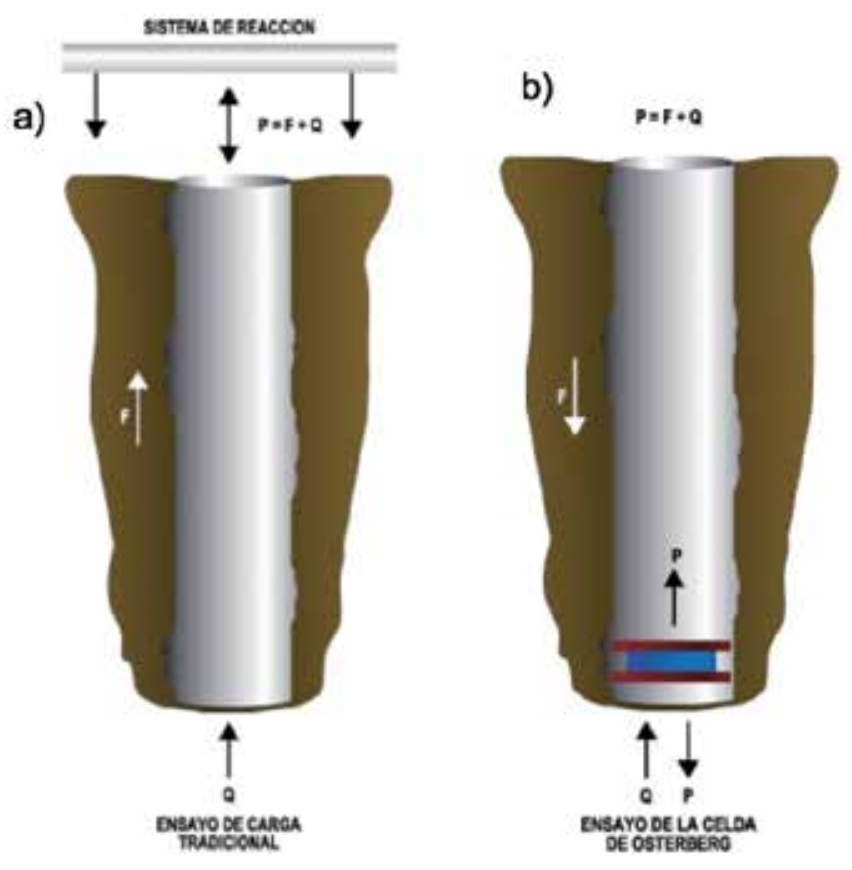

Figura 1: a) Prueba de carga tradicional y b) ensayo de celda de carga de Osterberg

En la Figura 2 se muestra un esquema de los elementos que actúan durante un ensayo de celda de carga O-cell, donde se identifica: a) una celda de carga que es el gato hidráulico que genera la fuerza bidireccional en el pilote, b) transductores de desplazamiento posicionados entre las placas inferior y superior de la O-cell, con esto se mide la expansión de la celda, c) tuberías anexadas a la armadura: tuberías (celeste en la imagen) que se extienden de la placa superior de la O-cell hasta más allá de la cabeza del pilote, en estas tuberías se introduce un transductor lineal de desplazamiento para medir la compresión elástica del pilote; la otra tubería une el control hidráulico con la celda de carga y suministra el agua a presión que permite la aplicación de la carga en la celda y d) computador y registrador de datos permiten que los datos sean registrados y almacenados automáticamente en intervalos pequeños de tiempo, además que permiten que vayan siendo graficados 
en tiempo real (Loadtest, 2011).

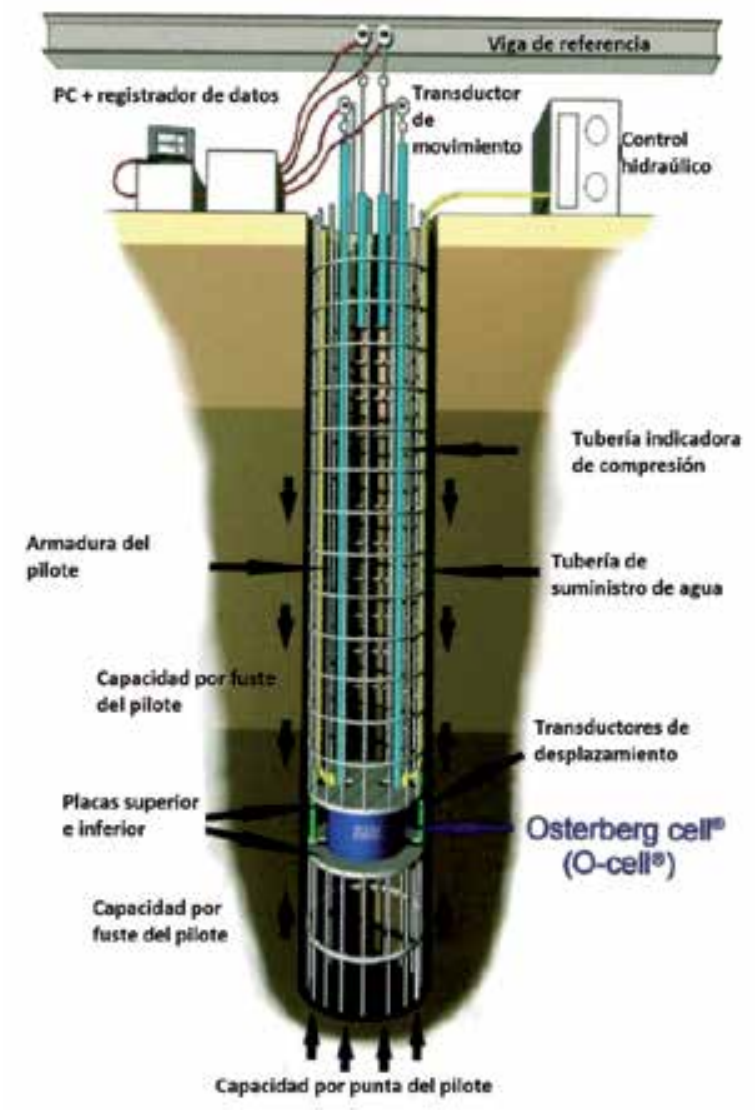

Figura 2: Esquema de funcionamiento e instrumentos del ensayo O-cell (Loadtest, 2011)

Para medir el desplazamiento y la carga se usan strain gauges, que son utilizados para medir la transferencia de carga sobre el pilote y obtener la capacidad por fuste. Es recomendable ubicar estos strain gauges según la estratigrafía del terreno, es decir, en diferentes horizontes con el propósito de discretizar la capacidad de fuste en los distintos niveles. Se utilizan también niveles automáticos para medir el movimiento absoluto de la cabeza del pilote, estos se ubican en un sistema apoyado lejos del pilote, usando una viga de referencia. La medición de la presión se hace por medio de un manómetro y del cable transductor de presión.

El resultado de la prueba son curvas de carga versus desplazamiento para la carga ascendente y para la carga descendente. La información obtenida de la prueba de celda de carga de Osterberg O-cell se puede trabajar de forma similar a la información obtenida por medio de un ensayo de carga tradicional con la carga aplicada en la cabeza del pilote (Seol y Jeong, 2009). Para obtener la curva equivalente al ensayo tradicional con los resultados de la prueba de O-cell se deben considerar 3 supuestos: 1) la curva fuerza por fricción versus movimiento ascendente obtenida por O-cell es igual a la curva de fuerza de compresión versus movimiento descendente de la cabeza del pilote en el ensayo convencional, 2) la curva fuerza descendente versus movimiento descendente obtenida por O-cell para la punta del pilote es igual a la curva de fuerza de compresión versus movimiento descendente en la punta del pilote en el ensayo convencional y 3) el pilote es rígido de modo que la parte superior e inferior tienen la misma deformación. La curva obtenida se debe corregir para incluir el efecto de compresión elástica que ocurre a lo largo del pilote, es decir, se tiene un incremento del desplazamiento para cada nivel de carga.

\section{Ensayo de carga 0-cell en RPC Concón}

En el año 2006, como parte de la ejecución de los pilotes de fundación para la planta Delayed Coker en la RPC ubicada en Concón, se realizaron una serie de ensayos en dos pilotes de más de $50 \mathrm{~m}$ de largo y $1.2 \mathrm{~m}$ de diámetro (Pilotes Terratest, 2006a). El conjunto de ensayos efectuados fueron: ensayos CSL (Crosshole Sonic Logging) para verificar la integridad de los pilotes; ensayos de carga con celda de Osterberg O-cell para la capacidad axial; ensayos de carga lateral con medición de desplazamiento en la cabeza y en profundidad de los pilotes. Los ensayos fueron efectuados por las empresas Pilotes Terratest S.A. y Loadtest International Inc.

En total, para el proyecto se ejecutaron 72 pilotes perforados de $1.2 \mathrm{~m}$ de diámetro con un total de $3365 \mathrm{~m}$ de excavación (Pilotes Terratest, 2011). Debido al tipo de suelo del proyecto y la alta profundidad de excavación requerida, los pilotes se ejecutaron con un sistema de perforación rotativa, utilizándose lodos tixotrópicos para el sostenimiento de las paredes de la excavación.

Las celdas O-cell utilizadas tenían $540 \mathrm{~mm}$ de diámetro, se localizó a $0.97 \mathrm{~m}$ de la punta en el pilote para el pilote $\mathrm{N}^{\circ} 1$ (Figura 3a). Se utilizaron 3 niveles de strain gauges entre la cabeza del pilote y la celda $\mathrm{O}$-cell en ambos pilotes (Figura $3 b$ ). En el pilote $\mathrm{N}^{\circ} 1$ la máxima carga bidireccional sostenida aplicada sobre el pilote fue de 15.85 MN. Para esa carga máxima, los desplazamientos sobre y bajo la 
O-cell fueron $9.83 \mathrm{~mm}$ y $9.49 \mathrm{~mm}$, respectivamente. Se intentó un escalón más de carga a $16.31 \mathrm{MN}$, pero se pudo mantener solo por 4 minutos antes que el sistema comenzara a perder presión. La Figura 3c muestra la instalación en la perforación del pilote de la armadura con el sistema de la O-cell.

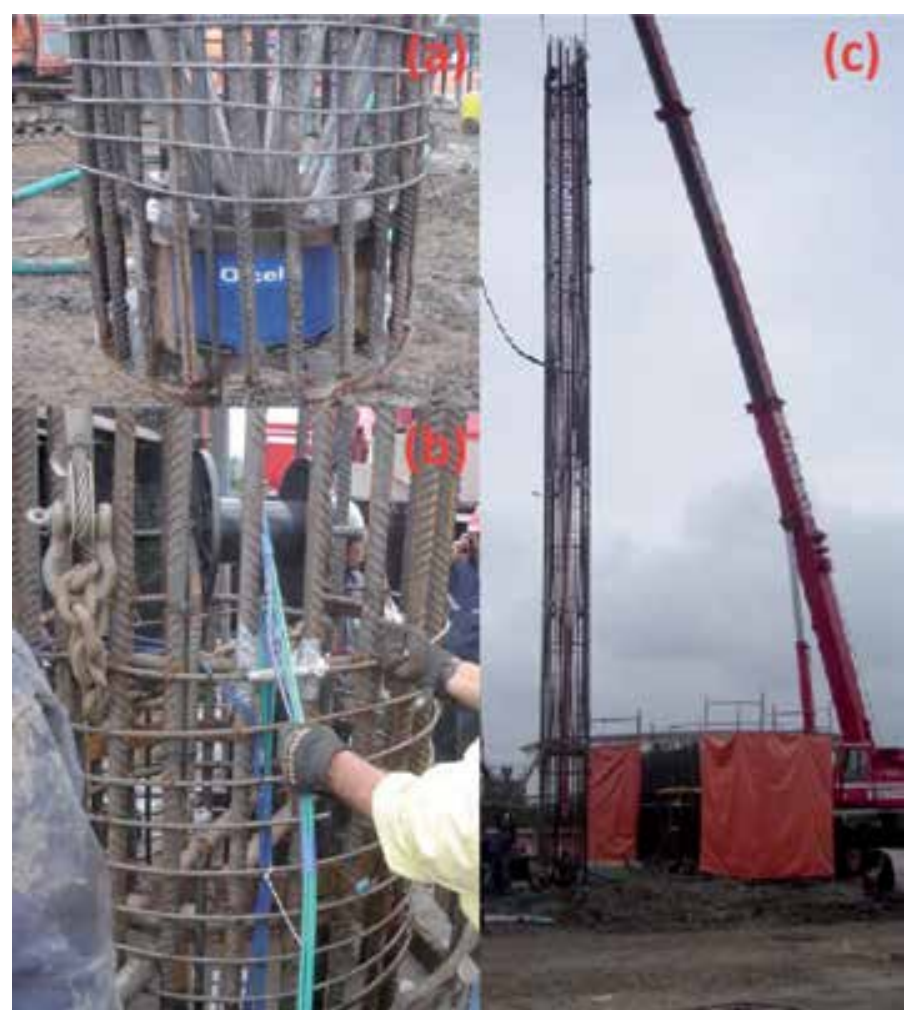

Figura 3: a) Celda Osterberg instalada en parte inferior de la armadura, b) cables para operar la celda desde la superficie y c) izaje de uno de los cuerpo de armadura para instalarlo en la perforación (Pilotes Terratest, 2006b)

El informe de mecánica de suelos del proyecto (Petersen, 2002) contiene las características estratigráficas y las propiedades de suelo en el terreno de la planta Coker de la Refinería de Concón. Adicionalmente, durante la ejecución de los pilotes de prueba, se realizó un registro estratigráfico de perforación (Loadtest, 2006). De manera breve se puede señalar que existe un depósito de suelo fino saturado, blando y normalmente consolidado de $35 \mathrm{~m}$ de espesor, que presenta baja consistencia, arcilloso, limo-arcilloso y/o arcillo-limo-arenoso. En segundo lugar, se define un estrato de unos $7 \mathrm{~m}$ de espesor consistente en una arcilla pre-consolidada y saturada de mediana a alta consistencia. Posteriormente se detecta un estrato duro de maicillo residual saturado, de muy alta consistencia y de unos 4 $\mathrm{m}$ de espesor. Por último, se detecta roca del basamento.
El nivel freático se detectó a los $4.7 \mathrm{~m}$ de profundidad desde la superficie. En el documento de mecánica de suelo (Petersen, 2002), se indican además las características necesarias del relleno estructural compactado existente a la fecha de los ensayos, ubicado en los primeros $5 \mathrm{~m}$ desde la superficie, el material de relleno se indica como arena gravosa y/o grava arenosa.

\section{Modelación numérica}

El método de elementos finitos es un tipo de modelación numérica que se puede utilizar para la modelación de problemas geotécnicos. La interacción entre suelo y estructura, con fuerzas externas es un caso de problema de equilibrio que está dentro del campo de aplicación de elementos finitos de ingeniería de fundaciones (Gussman et al., 2003).

Se utilizó el software Plaxis 2D 2014, programa computacional de elementos finitos para el análisis de estabilidad y deformaciones en problema geotécnicos (Brinkgreve, 2014a). Se realizaron dos modelos: 1) se modeló el ensayo de celda de Osterberg con una carga ascendente y otra descendente en la punta del pilote, usando los datos medidos en terreno en el ensayo de carga de Osterberg como datos de calibración y 2) se modeló el caso del ensayo tradicional de manera de comparar con la curva equivalente que se obtiene con los datos del ensayo O-cell.

Para modelar el pilote y el suelo que rodea a éste, se utilizó una configuración axial simétrica, ya que existe simetría radial. Se adoptó el modelo constitutivo del suelo llamado hardening soil, el cual es un modelo avanzado de comportamiento del suelo con el que se describe de forma más completa la variación de la rigidez del suelo (Brinkgreve, 2014b). El pilote fue modelado en forma lineal elástica, este tipo de relación se utiliza comúnmente para la modelación de elementos estructurales rígidos como lo es en este caso el pilote (Abbas et al., 2008).

Los principales parámetros necesarios para modelar el comportamiento del suelo con hardening soil son (Brinkgreve, 2014b): cohesión $c$, ángulo de fricción $\phi$, ángulo de dilatancia $\psi$, rigidez por carga triaxial o módulo secante $E_{50}$, rigidez por carga de compresibilidad o módulo tangente $E_{e d}$, rigidez por descarga triaxial $E_{u r}$ y dependencia de la rigidez del suelo con el nivel de esfuerzos $m$. La 
calibración del modelo del ensayo de celda de carga se llevó a cabo ingresando valores obtenidos de correlaciones con dos ensayos SPT y basados en la descripción de consistencia y compacidad. Además se consideró $E_{u r} \approx$ $3 E_{50} \mathrm{y} E_{50} \approx E_{e d}$ (Brinkgreve, 2014b). Los valores usados en la modelación se resumen en la Tabla 1.

Tabla 1: Valores de los parámetros de suelo utilizados en los modelos numéricos

\begin{tabular}{|l|c|c|c|c|c|c|c|c|}
\hline Estrato & $\begin{array}{c}\gamma_{\text {sat }} \\
\mathrm{kN} / \mathrm{m}^{3}\end{array}$ & $\begin{array}{c}c, \\
\mathrm{kPa}\end{array}$ & $\begin{array}{c}\phi, \\
\mathrm{o}\end{array}$ & $\begin{array}{c}\psi, \\
\mathrm{o}\end{array}$ & $\begin{array}{c}E_{50}, \\
\mathrm{MPa}\end{array}$ & $\begin{array}{c}E_{e d}, \\
\mathrm{MPa}\end{array}$ & $\begin{array}{c}E_{u r}, \\
\mathrm{MPa}\end{array}$ & $m$ \\
\hline Relleno & 21 & 0 & 36 & 0 & 80 & 80 & 240 & 0.5 \\
\hline $\begin{array}{l}\text { Arcilla } \\
\text { limosa }\end{array}$ & 19 & 50 & 0 & 0 & 20 & 20 & 60 & 0.5 \\
\hline Maicillo & 19 & 40 & 0 & 0 & 40 & 40 & 120 & 0.5 \\
\hline Arenisca & 21 & 200 & 36 & 0 & 120 & 120 & 360 & 0.5 \\
\hline
\end{tabular}

Se ha asumido que el suelo rodea completamente al pilote y que el diámetro del pilote se mantiene constante en toda su longitud. En el modelo del ensayo de celda de carga se aplica una fuerza bidireccional en la punta del pilote, simulando las cargas de la O-cell. La Figura 4a muestra el mallado del dominio utilizado en la modelación de las cargas aplicadas por la O-cell y la Figura 4b muestra el mismo mallado y dominio, pero aplicando la carga en la cabeza del pilote simulando una prueba de carga tradicional. De esta forma es posible comparar la curva equivalente

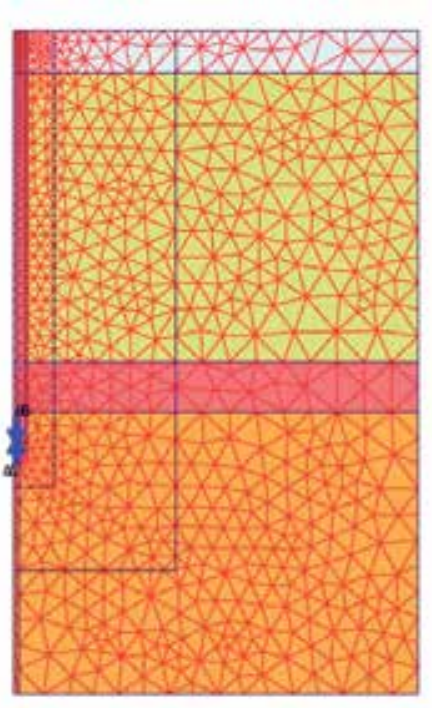

a)

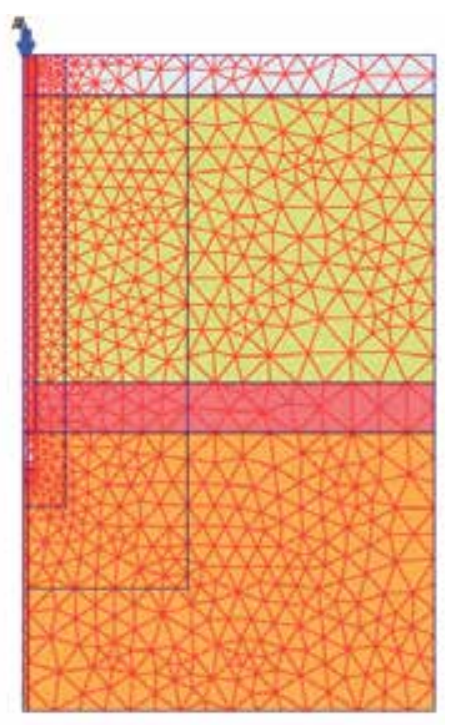

b)
Figura 4: Modelo realizado en Plaxis 2D para: a) simular en ensayo de carga de celda de Osterberg y b) para simular un ensayo de carga tradicional obtenida de la celda de Osterberg con la curva obtenida mediante el modelo de prueba de carga tradicional.

\section{Resultados de la modelación}

En las Figuras 5 y 6 se realiza la comparación gráfica entre las mediciones en terreno para el ensayo de carga con celda de Osterberg obtenidos del documento preparado por Loadtest (2006) y los resultados de la modelación numérica realizada en Plaxis 2D.

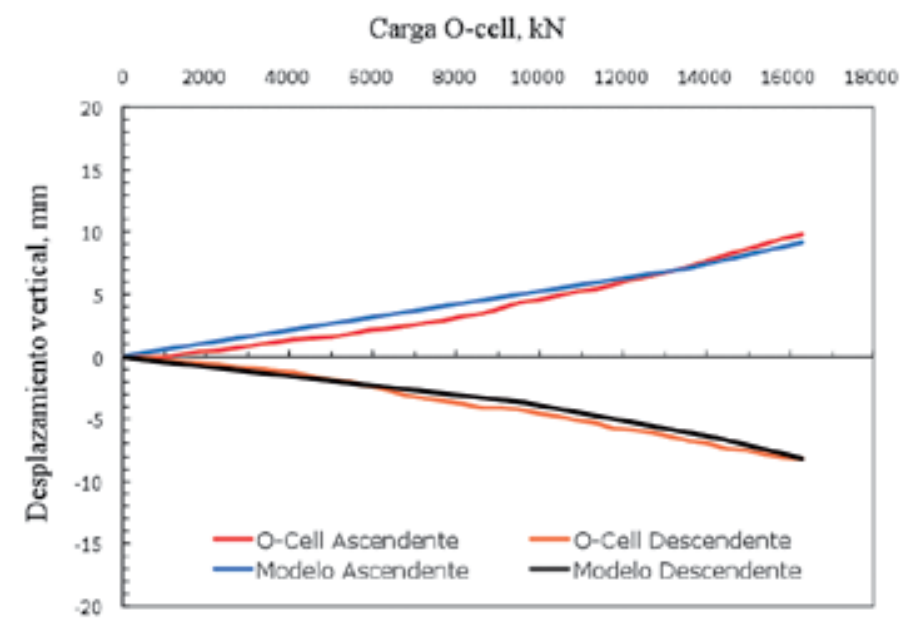

Figura 5: Comparación entre datos medidos en terreno y los resultados de la modelación

Como se observa en las curvas, la falla por fuste o punta no fue alcanzada, y las cargas máximas fueron limitadas por la capacidad última de la celda de carga. El movimiento ascendente corresponde a tracción y el descendente a compresión. Para el rango de carga analizado, la simulación resulta en una rigidez algo menor que la medida en compresión, en cambio en tracción la simulación es muy próxima a la medición.

La gráfica obtenida del ensayo presentó un desplazamiento inicial debido al suelo residual que está debajo del pilote. Para efectos de comparación se ha eliminado este asentamiento, es decir, se ha desplazado el inicio de la curva.

Además se muestra de forma gráfica en la Figura 6, la comparación entre la curva equivalente a un ensayo tradicional (carga aplicada en la cabeza del pilote), obtenida con los resultados del ensayo de carga O-cell entregado por Loadtest (2006) y la curva obtenida del modelo realizado en Plaxis 2D para el caso del ensayo tradicional. 


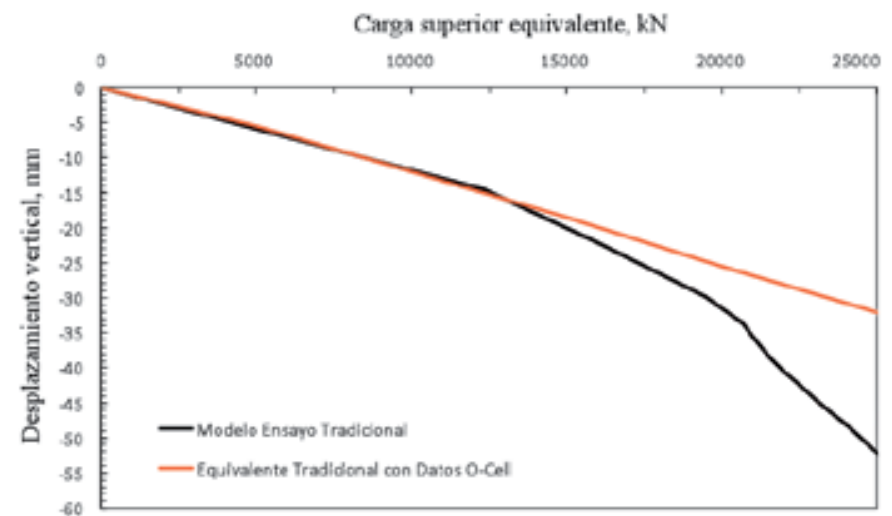

Figura 6: Comparación entre curva equivalente al ensayo tradicional (con datos del ensayo O-cell) y modelo realizado en Plaxis 2D

Se puede observar que hasta los $15 \mathrm{MN}$ de carga la curva del modelo se ajusta a la curva del caso tradicional, para luego separarse, siendo mayor el desplazamiento para la modelación numérica realizada.

\section{Conclusiones y recomendaciones}

Previo a la realización del ensayo O-cell es necesario contar con una completa información de la estratigrafía presente en el lugar. Con esto se puede definir la cantidad y ubicación de strain gauges a lo largo del pilote. También es importante recopilar información relativa a las técnicas usadas durante la ejecución de los pilotes, por ejemplo la capacidad de fuste de los pilotes se ve altamente influenciada por el tipo de sostenimiento usado en la excavación de los pilotes (por ejemplo camisas de acero o lodos bentoníticos). El uso de O-cell es económicamente conveniente cuando es necesario alcanzar altas cargas de pruebas, ya que por medio de pruebas de carga tradicionales el sistema de ejecución y reacción de carga en la superficie es muy costoso, y ocupa un área de trabajo importante en la superficie. La calidad de datos que entrega el ensayo de celda de Osterberg es muy alta y están por encima de la calidad de datos obtenidos mediante un ensayo tradicional, principalmente porque separa automáticamente y en tiempo real el comportamiento de la punta y fuste del pilote. Este tipo de ensayos se justifica en obras de gran envergadura y es recomendado realizarlo en una etapa previa al diseño final y ejecución de los pilotes, de manera de que los resultados puedan ser utilizados en el diseño final, disminuyendo incertezas. Esto se traduce en un diseño más seguro, pudiendo resultar además más económico, ya que como se indica en los estudios realizados por Osterberg (1999), las capacidades obtenidas por medio del ensayo son generalmente mayores que las estimadas por los ingenieros geotécnicos en etapas de diseño.

Utilizando mediciones de ensayos O-cell en la refinería de Concón se ha calibrado un modelo numérico de carga de pilotes usando el programa comercial Plaxis 2D. La calibración del modelo permite extrapolar la respuesta del pilote para cargas más altas que las medidas en terreno. Para el ensayo de carga tradicional se obtienen buenos resultados hasta los $15 \mathrm{MN}$. Las diferencias se pueden explicar en que la discretización usada en el modelo no fue representativa, lo cual significa que un mayor número de estratos sería necesario en la modelación. Otra razón, puede ser que, como se indica en el documento preparado por Loadtest (2006), la curva obtenida de los datos del ensayo O-cell corresponde a intervalos de tiempo de aplicación de carga de ocho minutos y no incluyen el efecto creep.

\section{Agradecimientos}

Los autores quieren agradecer a Pilotes Terratest por facilitar los antecedentes del ensayo que permitieron realizar la modelación. Además queremos agradecer a Denton Kort (Loadtest), por su buena disposición ante las consultas relativas al ensayo.

\section{Referencias}

Abbas J., Chik, Z. and Taha, M. (2008). Single pile simulation and analysis subjected to lateral load. Electronic Journal of Geotechnical Engineering 13 (E), 1-15

Aydin, M., Bradka, T., and Kort, D. (2011). Osterberg cell load testing on helical piles. In Han and Alzamora eds., Geo-Frontiers 2011: Advances in Geotechnical Engineering, ASCE, Reston, Virginia, 66-74

Brinkgreve, R.B.J. (2014a). Reference manual. Delft University of Technology \& Plaxis BV, Delft

Brinkgreve, R.B.J. (2014b). Material model manual. Delft University of Technology \& Plaxis BV, Delft

Candogan, A. (2009). The art and practice of foundation engineering. Ali Candogan, Estambul 
Castelli, R.J. and Wilkins, E. (2004). Osterberg load cell test results on base grouted bored piles in Bangladesh. In Tuerner and Mayne eds., GeoSupport 2004: Drilled shafts, micropiling, deep mixing, remedial methods, and speciality foundation systems. ASCE, Reston, Virginia, 587, 602

Coduto, D.P. (2000). Foundation design: Principles and practices. Prentice Hall, New Jersey

Das, B.M. (2012). Fundamentos de ingeniería de cimentaciones. Cengage Learning, México, D.F.

Ellman, R. and Rhyner, F.C. (2009). Bored pile foundation in offshore conditions. In Van Impe \& Van Impe eds., Deep Foundations on Bored and Auger Piles. Taylor \& Francis, London, 47-60

Gussmann, P., Schad, H. and Smith, I. (2003). Numerical methods. In Smoltczyk ed., Geotechnical Engineering Handbook Volume 1: Fundamentals. Ernst \& Sohn, Berlin, 437-479

Loadtest International Inc. (2006). Report on drilled pile load testing (Osterberg Method): Test Pile \#1 - RPC Delayed Coker Facility Concón, Chile

Loadtest International Inc. (2011). Loadtest. 36th Annual Conference on Deep Foundations, Boston (folleto comercial)

Osterberg, J.O. (1999). What has been learned about drilled shafts from the Osterberg load test. Deep foundation institute annual meeting 1999. http://www.loadtest.com/media/Learned\%20 from $\% 200$-cell.pdf
Peck, R.B., Hanson, W.E. and Thornburn, T.H. (1974). Foundation Engineering. John Wiley \& Sons, New York

Petersen, M. (2002). Informe de mecánica de suelos proyecto Planta Coker. Valparaíso

Pilotes Terratest (2006a). Informe final de ensayos efectuados sobre pilotes \#1 y \#2. Santiago.

Pilotes Terratest (2006b). Resumen de fotos ensayos RPC. Santiago.

Pilotes Terratest (2011). Proyecto: Planta Coker RPC de la Refinería de Petróleo Concón. Retrieved from: http://www. terratest.cl/documentos/FT-02251-02-rev2.pdf

Seol, H. and Jeong, S. (2009). Load-settlement behavior of rocksocketed drilled shafts using Osterberg-cell tests. Computers and Geotechnics 36, 1134-1141

Schmertmann, J.H. and Hayes, J.A. (1997). The Osterberg cell and bored pile testing - a symbiosis. Proceedings $3 \mathrm{rd}$ International Geotechnical Engineering Conference. Cairo University, Cairo, Egypt, 139-166

Zuo, G., Drumm, E.C., Zia Islam, M.Z. and Yang, M.Z. (2004). Numerical analysis of drilled shaft O-cell testing in mica schist. In Tuerner and Mayne eds., GeoSupport 2004: Drilled shafts, micropiling, deep mixing, remedial methods, and speciality foundation systems. ASCE, Reston, Virginia, 778-789 